\title{
Mortality indicators of COVID-19 in high burden states and cities of India: a review
}

\author{
Srinivas G.*, Sivabakya T. K., Rakesh A., Valarmathi S., Sudha Seshayyan
}

Department of Epidemiology, Tamilnadu Dr. MGR Medical University, Tamilnadu, India

Received: 08 September 2020

Revised: 02 November 2020

Accepted: 04 November 2020

\section{*Correspondence:}

Dr. Srinivas G.,

E-mail: drsrini@gmail.com

Copyright: (C) the author(s), publisher and licensee Medip Academy. This is an open-access article distributed under the terms of the Creative Commons Attribution Non-Commercial License, which permits unrestricted non-commercial use, distribution, and reproduction in any medium, provided the original work is properly cited.

\begin{abstract}
Understanding the dynamics of COVID-19 case-fatality and recovery rates would strengthen the knowledge base on the current trends of the epidemic's severity. During the outbreak, the case-fatality ratio (CFR) is commonly used in most countries. On average it raised from 3.4 percent (as of 25 February 2020) across countries to 7.0 percent (as of 21 April 2020) and then came down to 3.91 percent (as on 31st July 2020). This review was conducted according to the preferred reporting items for systematic reviews and meta-analyses (PRISMA) guidelines. The articles were searched from databases like PubMed, the Cochrane library and Science Direct combining MeSH and free-text terms. In India, the states of Maharashtra and Madhya Pradesh had higher CFR levels as against the southern states of Kerala and Tamil Nadu with significantly lower CFR. India's total number of COVID-19 fatalities per million population is one of the lowest in the world measuring 27.02 per million. Weekly death rate measures of India are lowest affecting 0.29 per 1000 inhabitants. Of the major cities of India, Chennai showed upward trend with a highest weekly death rate in the last week of July 2020, accounting for 2.02 deaths per 1000 inhabitants. This article attempts to provide an over view of key mortality indicators to measure COVID-19 deaths and assess the mortality trends of selected cities and states in India during the months of June and July 2020.
\end{abstract}

Keywords: COVID-19, Mortality, Case fatality rate, Deaths, India, Metropolitan cities

\section{INTRODUCTION}

What gets measured can be managed better and what can be managed arrives at a more explicit inference. Mortality rate is one of the most appropriate indicators used to measure the overall impact of a pandemic on the country/state as well as to understand the effectiveness of the control measures taken. The commonly studied mortality rates include crude death rate, Specific death rates (SDR, that can be specific to a particular disease, age group, gender or time), case fatality ratio, proportional mortality rate, survival rate and adjusted/standardized rate. If the decline in the rate of death is tracked using a suitable indicator, it provides a clear insight to understand and evaluate the efficiency of the containment strategies that are in action. ${ }^{1}$ The ultimate public health objective of any pandemic is to contain the number of death and damage mortality and morbidity as far as possible. Systematic tracking of death rates is crucial for understanding and counteracting the impact of the epidemic, even though the number of deaths is not a completely reliable indicator of the spread of the corona virus. ${ }^{2}$ Also, tracking deaths will identify through the trends of increase of infections missed by testing and tracking systems, and will provide an early warning if deaths from other conditions increase. One of the most important ways to measure the burden of COVID19 is mortality. ${ }^{3}$ The metrics employed by many countries and states to obtain the burden of morbidity or mortality largely remains crude, and includes data related to the daily number of confirmed cases, tests, deaths and hospitalization rates. Most of the rates and ratios thus calculated, lag behind the actual transmission of the corona 
virus, at least by one to three weeks. Thus, there is a desperate need for collecting/obtaining/consolidating better data that helps to track the progression of the pandemic, preferably real-time. ${ }^{4,5}$ By its inherent nature, the case fatality rate and its reported mortality have limitations caused by the factors mentioned below.

\section{Differences in the number of people tested}

With more testing, more people with milder symptoms are identified. This lowers the case-fatality rate. ${ }^{6}$

\section{Demographics}

For example, mortality tends to be higher in the older population. $^{7}$

\section{Characteristics of the healthcare system}

For example, mortality may rise as hospitals become overwhelmed and have fewer/depleting resources.

Other factors, many of which remain unknown. ${ }^{8}$

Although underestimation of CFRs risks the population not taking the threat seriously, overestimation might lead to unnecessary additional panic and concern. During a rapidly evolving pandemic, accurate measures of disease characterization are important.

\section{METHODS}

This paper compiled data of COVID-19 from the covid19india.org website and other official websites of the state, which is a data-sharing portal that provides the most updated information for each affected state about the daily and total confirmed cases, recovered cases, and deaths.

\section{Mortality indicators considered}

\section{Case fatality rate}

Case fatality rate (CFR) estimate is based on the ratio of the number of deaths for a particular disease to the number of confirmed cases of infection. Notably, the exact denominator remains indefinite as the asymptomatic cases or the patients with very mild symptoms might not be tested or identified at all. As per reports so far, more than $80 \%$ of the people who tested positive for SARS-CoV-2 infection have not presented with any symptom of the disease. This indicates that there must be many more people in the population who would be infected but not tested as they don't show up any suspected symptom of COVID-19. CFR predominantly depends upon the number of cases who are diagnosed and labelled as 'cases', which in turn depends upon the testing rate, reporting rate, etc. ${ }^{9,10}$ If a greater number of tests is performed, the denominator (used to calculate CFR) will keep increasing, and for a disease like COVID-19, with the number of asymptomatic/mildly symptomatic cases being high, it could capture many such asymptomatic/mildly symptomatic cases, and this would further lower the CFR. Moreover, the robustness of the diagnostic test also plays some role here in terms of false-positive rate, falsenegative rate, etc. The CFR, therefore, may not be a robust indicator of mortality/fatality/progression of the disease. ${ }^{11}$ The reported CFR (indicating the killing power of disease, closely related to the virulence of the disease and its causative factor) vary from state/city (range 1.6 to $14.8 \%$ ) and is shown in Figure 1.

\section{Case Fatality Rate in the major States \& Cities of India}

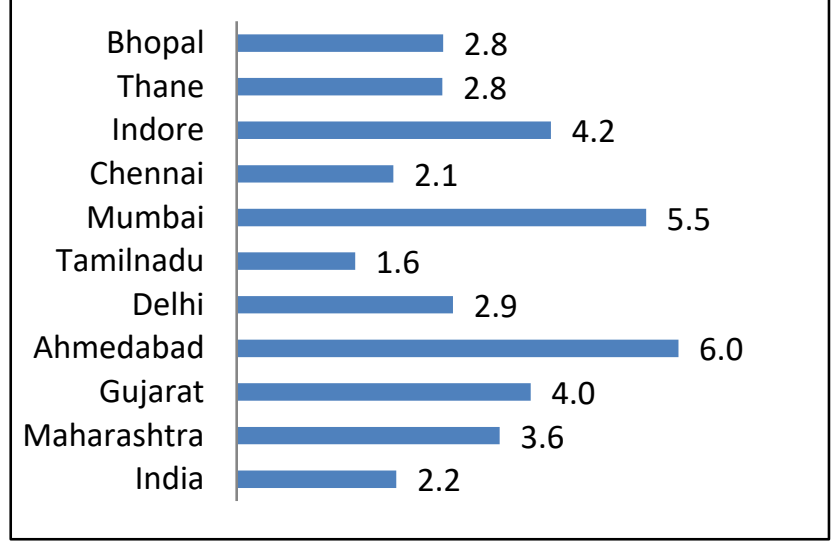

Figure 1: CFR in the major states and cities of India (as on 31 July 2020).

\section{Deaths due to COVID-19 per million population}

The mortality rate that is calculated concerning the population (Figure 2) gives a combined measure of success of both containment as well as case management and helps to understand is we have control over the epidemic (trend showing that number of deaths coming down). The rate may underestimate the number of deaths, but still, the proportion by which these are undercounted will remain generally steady over some time. Also, out-of-hospital deaths - particularly those who have not been tested - may create an artifact; this artifact can be minimized through what is called the "verbal autopsy technique". ${ }^{12}$ By this technique, the family members, friends, or close companions are interviewed regarding the symptoms that the deceased exhibited; based on the information given, it would be possible, to a large extent, to determine if the deceased had any COVID-19 symptom. $^{13}$ India has reported a death rate of 27.02 deaths per million population so far (as on 31 July 2020), for COVID-19. Indian states and districts that have recorded the maximum death rate are Mumbai (311.25) followed by Delhi (208.3), Chennai (192.32), Ahmedabad (172.64), Thane (140.52), Maharashtra (121.38) and Indore (103.08). Some of the states and cities with lowest recorded death rate per million includes Bhopal (73.64), Tamilnadu (47.76) and Gujarat (37.63). If the deaths per million in major cities alone are 
taken into consideration, Mumbai has reported a greater number of deaths than any other city (Figure 2).

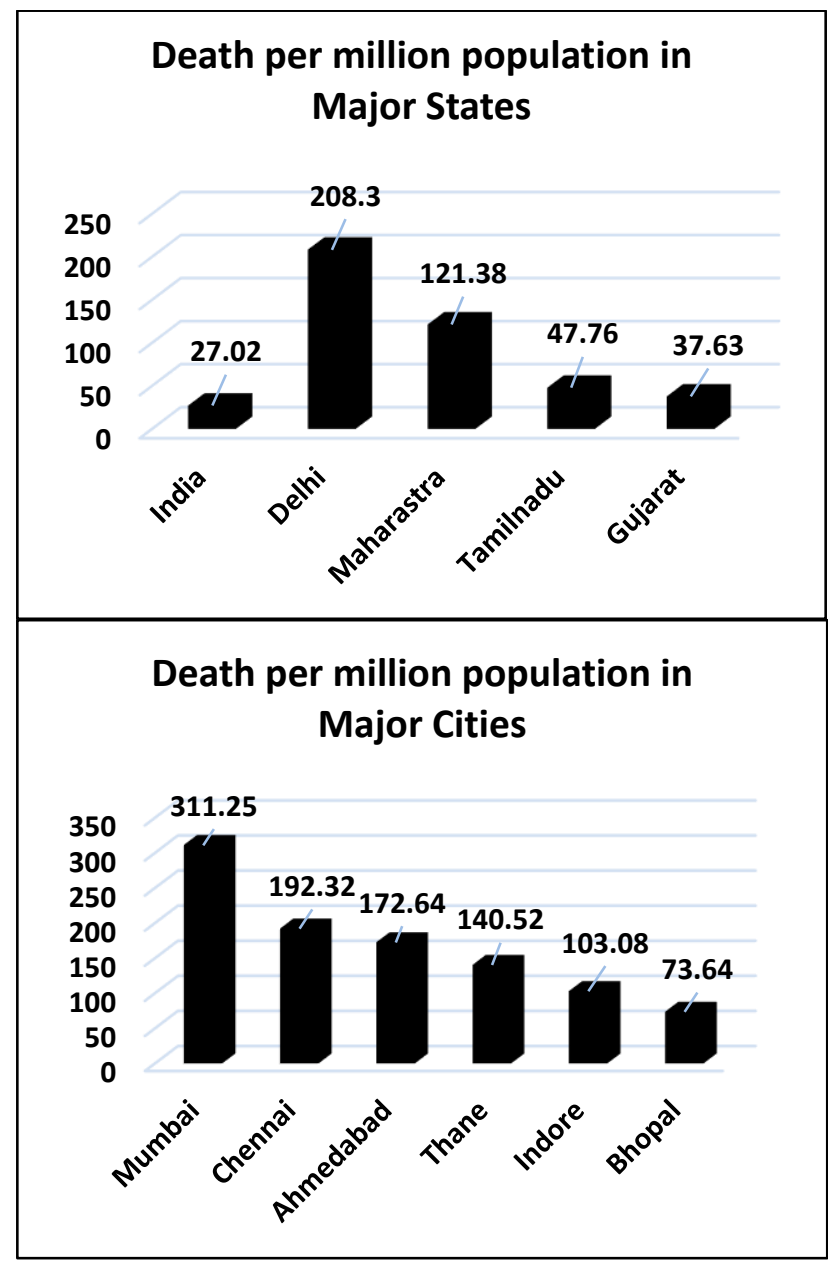

Figure 2: COVID-19 death per million population in major states and cities (as on 31 July 2020).

\section{Weekly death rate of COVID-19}

If the number and/or rate of death rises very slowly (deaths per week), it means that the pandemic is under a good control and the severity of the disease is low. A comparison may be drawn between the deaths data of all causes needs to be considered (Figure 3). Excess deaths on a weekly basis may offer the most accurate and equivalent way to measure the severity of the pandemic and formulate lessons to be learned. This method allows estimation of the pandemic's overall mortality impact at different locations. ${ }^{14}$ The weekly death rate was calculated using the following formula for 1000 inhabitants.

\section{Weekly death rate}

$=$ Number of deaths in a week $\times 52$ /midyear population $\times 1000$

Chennai have recorded the highest death rate as on the last week on July with 6.64, followed by Thane (1.84), Mumbai (1.33) and Bhopal (1.00). The lowest death rate was recorded in Ahmedabad (0.37) and Indore (0.40).

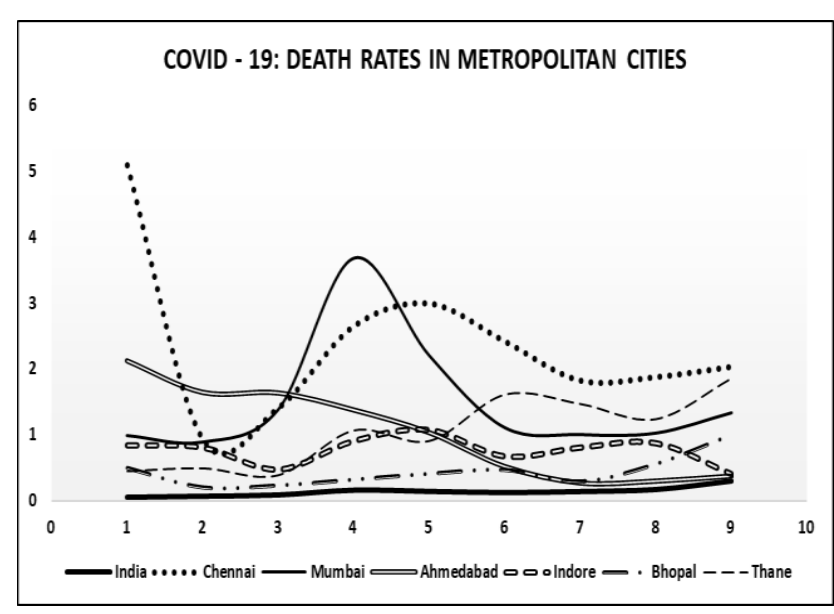

Figure 3: COVID-19: weekly death rate in May, June and July.

\section{DISCUSSION}

The reported CFRs vary greatly from country to country (range $0-17 \%$ ). Globally, CFR is seen to be rising sharply in those aged over 60 years and is the highest in those aged over 80 years $(>20 \%)$. China, which initially saw a CFR greater than $10 \%$, now has a CFR of $0.7 \%$ as its fatality rate will ultimately be determined to be nearly or just below $1 \% .{ }^{15}$ However, these mortality rates are focused on the number of fatalities compared to the number of reported infection cases, and is not indicative of the real death rate; patients who die on any particular day were diagnosed even sooner, and therefore the mortality rate denominator would be the cumulative number of patients diagnosed at the same time as those who died. Notably, the full denominator remains unknown because it is possible that asymptomatic cases or patients with very mild symptoms will not be tested and identified. ${ }^{16}$ Therefore, these reports cannot be used in the calculation of real death levels, because actual figures apply to clinically evident reports COVID-19. Current evidence suggests that older individuals and those with compromised immune systems from pre-existing conditions are more likely to develop severe forms of epidemic winds down. Thus there is a need for additional indicators such as age specific mortality indicator and specific risk factor analysis through in-depth auditing of medical records (COVID-19 cases with mortality and without mortality) to gain insights on the deaths. And in order to get a better estimate of the absolute number of deaths due to COVID-19, have the certified deaths as well as the verbal autopsy documented deaths particularly for out-of-hospital deaths and for those who have not been tested besides estimating the COVID-19 deaths against non-COVID-19 deaths through modeling studies.

\section{CONCLUSION}

In conclusion, the commonly used mortality indicators and their estimates illustrate a need for additional indicators adjusting for age, co-morbid conditions and other risk 
factors among Covid-19 cases and for in depth auditing of deaths. This may identify interventions that are required to reduce deaths and help the living.

Funding: No funding sources

Conflict of interest: None declared

Ethical approval: Not required

\section{REFERENCES}

1. National Research Council (US) Panel on Statistics for an Aging Population; Gilford DM, editor. The Aging Population in the Twenty-First Century: Statistics for Health Policy. Washington (DC): National Academies Press (US); Social, Economic, and Demographic Changes among the Elderly. 1988. Available at: https://www.ncbi.nlm.nih.gov/books /NBK217734/. Accessed on: 25 February 2020.

2. Hernandez JBR, Kim PY. Epidemiology Morbidity And Mortality. In: StatPearls [Internet]. Treasure Island (FL): StatPearls Publishing. 2020.

3. Tang B, Bragazzi NL, Li Q, Tang S, Xiao Y, Wu J. An updated estimation of the risk of transmission of the novel coronavirus (2019-nCov). Infect Dis Model. 2020;5:248-55.

4. Chung KC, Shauver MJ. Measuring quality in health care and its implications for pay-for-performance initiatives. Hand Clin. 2009;25(1):71-7.

5. Naing NN. Easy way to learn standardization: direct and indirect methods. Malays J Med Sci. 2000;7(1):10-5.

6. Onder G, Rezza G, Brusaferro S. Case-Fatality Rate and Characteristics of Patients Dying in Relation to COVID-19 in Italy. JAMA. 2020;323(18):1775-6.

7. Committee on Guidance for Establishing Crisis Standards of Care for Use in Disaster Situations; Institute of Medicine. Crisis Standards of Care. A Systems Framework for Catastrophic Disaster Response. Washington (DC): National Academies Press (US); Mar 21. Hospitals and Acute Care Facilities. 2012.

8. Institute of Medicine (US) Forum on Microbial Threats. Ethical and Legal Considerations in
Mitigating Pandemic Disease: Workshop Summary. Washington (DC): National Academies Press (US). Strategies for Disease Containment. 2007.

9. Chang CS, Yeh YT, Chien TW, Lin JCJ, Cheng BW, Kuo SC. The computation of case fatality rate for novel coronavirus (COVID-19) based on Bayes theorem. Medicine. 2020;99(21):19925.

10. Giorgi Rossi P; Emilia-Romagna COVID-19 working group, Broccoli S, Angelini P. Case fatality rate in patients with COVID-19 infection and its relationship with length of follow up. J Clin Virol. 2020;128:104415.

11. Ward MM. Estimating disease prevalence and incidence using administrative data: some assembly required. J Rheumatol. 2013;40(8):1241-3.

12. Thomas LM, D'Ambruoso L, Balabanova D. Verbal autopsy in health policy and systems: a literature review. BMJ Glob Health. 2018;3(2):000639.

13. Khafaie MA, Rahim F. Cross-Country Comparison of Case Fatality Rates of COVID-19/SARS-COV-2. Osong Public Health Res Perspect. 2020;11(2):7480.

14. Madhav N, Oppenheim B, Gallivan M. Pandemics: Risks, Impacts, and Mitigation. In: Jamison DT, Gelband H, Horton S, editors. Disease Control Priorities: Improving Health and Reducing Poverty. 3rd edition. Washington (DC): The International Bank for Reconstruction and Development/The World Bank. Chapter 17. 2017.

15. Baud D, Qi X, Nielsen-Saines K, Musso D, Pomar L, Favre G. Real estimates of mortality following COVID-19 infection. Lancet Infect Dis. 2020;20(7):773.

16. Hu Y, Sun J, Dai Z. Prevalence and severity of corona virus disease 2019 (COVID-19): a systematic review and meta-analysis. J Clin Virol. 2020;127:104371.

Cite this article as: Srinivas G, Sivabakya TK, Rakesh A, Valarmathi S, Seshayyan S. Mortality indicators of COVID-19 in high burden states and cities of India: a review. Int J Community Med Public Health 2021;8:507-10. 